\title{
Exploiting trends in the foreign exchange markets
}

\author{
Adrián Fernández-Pérez ${ }^{\mathrm{a}}$, Fernando Fernández-Rodríguez ${ }^{\mathrm{a}}$ and \\ Simón Sosvilla-Rivero ${ }^{\mathrm{b}, *}$ \\ ${ }^{a}$ Departamento de Métodos Cuantitativos, Facultad de Ciencias Económicas \\ y Empresariales, Universidad de Las Palmas de Gran Canaria, Campus de \\ Tafira, 35017 Las Palmas de Gran Canaria, Spain \\ ${ }^{\mathrm{b}}$ Departamento de Economía Cuantitativa, Facultad de Ciencias Económicas \\ y Empresariales, Universidad Complutense de Madrid, Campus de \\ Somosaguas, 28223 Madrid, Spain
}

We offer further evidence on the relevance of technical trading in exchangerate markets using daily data for 95 currencies against the US dollar. To that end, we investigate the profitability of a simple technical trading rule based on Taylor's (1980) price trend model, generating optimal one-stepahead forecasts of returns using genetic algorithms. These trading rules, that bear similarity to the popular trading rules based on moving averages, overcome the buy-and-hold strategy in 25 of 39 cases where trends are detected, even in the presence of transaction costs.

Keywords: exchange rates; price trend model; genetic algorithms; trading rules

JEL Classification: C53; F31; G14

\section{Introduction}

In the companion paper (Fernández-Pérez et al., forthcoming), we tested for the existence of trends in exchange-rate series for 95 currencies against the US dollar. To that end, we made use of Taylor's (1980) price trend model that concentrates on the short-term pattern of the price trend and, employing a maximum likelihood method and a genetic algorithm to estimate the model, we found evidence in favour of the presence of trends in 39 of the 95 cases considered, with trends more frequent in intermediate exchange-rate regimes.

In this article we undertake the analysis of the profitability of a simple technical trading rule based on Taylor's price trend model. To that end, optimal onestep-ahead forecasts of returns are derived using a genetic algorithm and trading rules based on these forecasts are constructed. We have applied this investment strategy to daily data on 95 countries from 4 January 1993 to 31 December 2010.

Numerous authors support that, even after taking into account interest rate differentials and transaction costs, standard moving average rules yield excess profits for most of the US-dollar exchange rates. Besides, by using artificial data instead of actual foreign exchange data, this profitability is found to be statistically significant. In this sense, see Dooley and Shafer (1983), Levich and Thomas (1993), Neely et al. (1997), LeBaron (1998), Chang and Osler (1999), Gençay (1999), Dewachter (2001) and Harris and Yilmaz (2009), among others.

The rest of this article is organized as follows: Section II presents Taylor's (1980) price trend model. Section III describes the data set and reports our empirical results. Finally, Section IV provides some concluding remarks.

*Corresponding author. E-mail: sosvilla@ccee.ucm.es 


\section{Taylor's Price Trend Model}

Taylor's (1980) trend model for a prices time series $P_{t}$ is defined as

$$
\begin{aligned}
& x_{t}=\log \left(P_{t}\right)-\log \left(P_{t-1}\right)=\mu_{t}+\varepsilon_{t}, \\
& E\left(\varepsilon_{t}\right)=E\left(\varepsilon_{t} \varepsilon_{t+i}\right)=0, \quad i \neq 0, \operatorname{cov}\left(\mu_{s}, \varepsilon_{t}\right)=0 \quad \forall s, t
\end{aligned}
$$

where the white noise series $\varepsilon_{t}$ is uncorrelated with the stochastic process $\mu_{t}$ representing the trend in the model and it is interpreted as the response to anticipated changes in the supply and demand of the assets. This $\mu_{t}$ may be positive or negative giving rise to increasing or decreasing price trends, respectively. We also define $\sigma^{2}$ as the variance of $\varepsilon_{t}, v^{2}$ as the variance of $\mu_{t}$ and $\bar{\mu}$ as the expectation of $\mu_{t}$.

So, the trend model may be formulated with probability as

$$
\mu_{t}= \begin{cases}\mu_{t-1} \quad \text { with probability } \quad p \\ \bar{\mu}+\eta_{t} \quad \text { with probability } 1-p\end{cases}
$$

where $\eta_{t}$ is white noise with mean zero and independent of the past trend values $\mu_{s}$ for $s<t$.

The number of days that the duration of the trend is expected is given by a parameter $m$ (the so-called mean trend duration), and is defined as the averages of the different durations of possible trends

$$
m=\sum_{i=1}^{\infty} i(1-p) p^{i-1}=(1-p)^{-1}
$$

Omitting technical details which can be found in Taylor and Kingsman (1978), Taylor (1980) and Taylor (2008), the base of the price trend test is the existence of positive correlations between daily rescaled returns $x_{t} / \hat{a}_{t}$ with several lags, where $\hat{a}_{t}$ represents the estimation of the mean absolute deviation which is considered a proxy of the variance of the returns $x_{t}$. On the contrary, in the random walk model, all correlations will be 0 for any lag.

The correlations of daily rescaled returns are defined as $\rho_{i}=\operatorname{cor}\left(x_{t} / \hat{a}_{t}, x_{t+1} / \hat{a}_{t+1}\right)$. Taylor shows that model (1) with $\mu_{t}$ variable as in Equation 2 provides the following correlation expression for rescaled returns:

$$
\rho_{i}=\frac{p^{i} v^{2}}{v^{2}+\sigma^{2}}=A p^{i}
$$

where $A=v^{2} /\left(v^{2}+\sigma^{2}\right)$.

So Taylor (1980) formulated a hypothesis test where the null corresponds to the random walk:

$$
H_{0}: \rho_{i}=0, \text { for each } \mathrm{i}>0
$$

meanwhile, the alternative hypothesis to the random walk model is

$$
\begin{array}{r}
H_{1}: \rho_{i}=A p^{i}, \text { for some } A \geq 0 \\
0 \leq p \leq 1, \text { for each } i>0
\end{array}
$$

The parameter $A$ is a measure of information that is not instantaneously reflected in the market prices, meanwhile $p$ measures the speed at which the information is reflected in them. If $A$ or $p$ were very close to 0 , the information would be used perfectly by the market. But when the trend is accepted, $A$ has a small value, around $3 \%$, and $p$ is close to 1 . It means that the market has a slow interpretation of the relevant information that arrives.

Due to the complexity of the log-likelihood function, in order to estimate the parameters, a genetic algorithm is employed (see Dorsey and Mayer (1995) for the use of genetic algorithms for optimizing complex likelihood functions in econometrics). Once the parameters associated with the trend model have been estimated, it is possible to construct technical trading strategies in order to beat the market. We will employ the strategy developed by Taylor (2008) aimed to profit from substantial trends in either direction. This strategy is compounded by three control parameters $k_{1}, k_{2}$ and $k_{t}$ where $k_{1}>k_{2}$. The parameter $k_{1}$ controls the commencement of trades, telling us when to change a short position for a long position. The parameter $k_{2}$ controls the conclusion of the trades, telling us when to change a long position for a short position.

Trading decisions depend on a standardized forecast $k_{t}$ calculated by assuming the trend model, that is,

$$
k_{t}=\frac{f_{t-1,1}}{\hat{\sigma}_{F, t-1}}
$$

where

$$
\begin{gathered}
f_{t-1,1}=\left(\hat{a}_{t} / \hat{a}_{t-1}\right)\left\{(p-q) x_{t-1}+q f_{t-2,1}\right\} \\
\hat{\sigma}_{F, t-1}=\hat{a}_{t}\{A p(p-q) /(1-p q)\}^{1 / 2}
\end{gathered}
$$

with $t=21, \ldots, n_{\text {rend }}$, where $n_{\text {rend }}$ is the total number of returns. In the recursion (8), $f_{t}, 1$ is the prediction from an Autoregressive Moving Average model with 1 autoregressive term and 1 moving average term, $A R M A(1,1)$ made in the instant $t$ of the return $t+1$, $\hat{\sigma}_{F, t}$ is its $\mathrm{SD}, x_{t}$ is the no rescaled return of the series in the instant $t$ and $\hat{a}_{t}$ is the estimated mean absolute deviation.

The Taylor strategy is as follows: we need 20 returns before the beginning in order to estimate the mean 
absolute deviations $\left(\hat{a}_{t}\right)$. The values of $f_{t, 1}$ and $\sigma_{F, t}$ are assumed to be 0 for $t \leq 20$, and for $t \geq 21$ are estimated recurrently in Equations 8 and 9. After $t \geq 21$, we begin with no market position until $k_{t}>k_{1}$ (start a long position) or $k_{t}<k_{2}$ (start a short position).

When we are inside the market, if we are in a long position we change to a short position when $k_{t}<k_{2}$; if we are in a short position we change to a long position when $k_{t}>k_{1}$. For $k_{t} \in\left[k_{1}, k_{2}\right]$ do not change the position in any case. When we change our position from long to short or vice versa, a transaction cost of $0.05 \%$ is subtracted from the total return. Besides, in order to compute total returns, we assume that, when we are in a short position, the proceeds are invested in a money market account with a risk-free rate of $4 \%$ per annum (a year of 252 days is assumed).

In order to select the control parameters $k_{1}$ and $k_{2}$, an optimization process is carried out. So, $k_{1}$ and $k_{2}$ are selected, maximizing the Sharpe ratio of the Taylor strategy in the training period. With that end a genetic algorithm is also employed.

Once the control parameters are estimated they are employed, together with the trend parameters $(A, p$ and $q$ ) obtained in the training period, in the prediction period. The net return obtained in the period $t$ to the series $i$ is the following:

$$
R_{i}^{t}=\sum_{t=21}^{N_{\text {rend }}}\left(x_{t} b u y_{t}\right)+\sum_{t=21}^{N_{\text {rend }}}\left[\left(x_{t}-\text { riskf }_{i}\right) \text { sell }_{t}\right]-c_{i} \text { mov }_{t}
$$

where $x_{t}$ is the no rescaled return, $b u y_{t}$ stands for a buy signal in the instant $t$ (equal to 1 when we are in a long position and equal to 0 when we are in a short position or we take no market position), $c_{i}$ is the transaction cost $(0.05 \%)$, mov $_{t}$ is the number of times that we change from a short to a long position and vice versa, riskf $_{i}$ is the risk-free return (4\% per annum) and sell $_{t}$ stands for the sell signals (equal to -1 when we are in a short position and equal to 0 when we are in a long position or we take no market position).

Note that, as technical trading is often criticized on the grounds that the profits generated may be illusory given the existence of transaction costs (see e.g. Korajczyk and Sadka (2004) and Lesmond et al. (2004)), we explicitly incorporate such costs in computing the net returns from our trading strategy based on the price trend model.

In order to compare the mean net return of the Taylor strategy with the mean net return of the buyand-hold strategy, the Sharpe ratio is employed. It divides the net return by its SD, which for the series $i$ in the period $t$ is defined as

$$
\operatorname{Sharpe}_{i}^{t}=\frac{R_{i}^{t} / N_{\text {return }}}{\sigma_{R_{i}^{t}}}
$$

where $N_{\text {return }}$ represents the number of returns considered in the period.

The buy-and-hold strategy returns are obtained by adding the returns of the series from the first to the last and subtracting two transaction costs corresponding with a buy in the first return and a sale in the last return.

\section{Data and Empirical Results}

In this article we use daily data of nominal exchange rates against the US dollar for 95 countries from 4 January 1993 to 8 August $2008^{1}$ taken from Reuters' EcoWin Pro.

Given that the countries in our sample present different exchange-rate regimes that could affect the existence of trends, we have used the 'natural fine classification' of Reinhart and Rogoff (2004), updated until December 2010 by Ilzetzki et al. (2011), to distinguish between a wide range of de facto regimes:

(1) No separate legal tender

(2) Pre-announced peg or currency board arrangement

(3) Pre-announced horizontal band that is narrower than or equal to $\pm 2 \%$

(4) De facto peg

(5) Pre-announced crawling peg

(6) Pre-announced crawling band that is narrower than or equal to $\pm 2 \%$

(7) De facto crawling peg

(8) De facto crawling band that is narrower than or equal to $\pm 2 \%$

(9) Pre-announced crawling band that is wider than or equal to $\pm 2 \%$

(10) De facto crawling band that is narrower than or equal to $\pm 5 \%$

(11) Moving band that is narrower than or equal to $\pm 2 \%$ (i.e. allows for both appreciation and depreciation over time)

(12) Managed floating

(13) Freely floating

(14) Freely falling

(15) Dual market in which parallel market data are missing.

Table 1 reports the values of parameters $q, k_{1}$ and $k_{2}$ for the training period and the returns, obtained in the prediction period (1 January 2008 until 31 December 2010), by both the Buy and Hold (B\&H) strategy and

\footnotetext{
${ }^{1}$ This period differs between series depending on data availability.
} 
Table 1. Parameters of Taylor's strategy and prediction performance statistics

\begin{tabular}{|c|c|c|c|c|c|c|c|c|}
\hline Currencies & Last regime & $q$ & $k_{1}$ & $k_{2}$ & $\mathrm{~B} \& \mathrm{H}$ & Sharpe-B\&H & Taylor & Sharpe-Taylor \\
\hline Euro & 14 & 0 & 0 & 0 & 0.0081 & 0.0077 & 0 & 0 \\
\hline Algeria dinar & 8 & 0 & 0 & 0 & -0.0826 & -0.0856 & 0 & 0 \\
\hline Angola adjusted kwanza & 4 & 0.6288 & 1.0973 & -1.4009 & -0.0010 & -0.0183 & -0.0007 & -0.0123 \\
\hline Argentina peso & 8 & 0 & 0 & 0 & -0.0412 & -0.1350 & 0 & 0 \\
\hline Australian dollar & 13 & 0 & 0 & 0 & -0.0218 & -0.0168 & 0 & 0 \\
\hline Bangladesh taka & 7 & 0 & 0 & 0 & 0.0031 & 0.0306 & 0 & 0 \\
\hline Barbados dollar & 2 & 0 & 0 & 0 & 0.0040 & 0.0651 & 0 & 0 \\
\hline Belize dollar & 2 & 0 & 0 & 0 & -0.0015 & -0.0084 & 0 & 0 \\
\hline Bhutan ngultrum & 2 & 0.9316 & 1.6548 & -1.4455 & 0.1000 & 0.1710 & 0.0286 & 0.0503 \\
\hline Bolivia boliviano & 7 & 0 & 0 & 0 & -0.0729 & -0.1619 & 0 & 0 \\
\hline Brazil real & 12 & 0.9759 & 0.6231 & -0.1461 & -0.0930 & -0.0689 & 0.1034 & 0.0896 \\
\hline Brunei Darussalam rínggit & 8 & 0.9822 & 1.2265 & -0.0517 & -0.0215 & -0.0415 & 0.0169 & 0.0351 \\
\hline Burundi franc & 8 & 0.8666 & 0.7009 & -0.1473 & 0.0581 & 0.0948 & -0.0313 & -0.0656 \\
\hline Cambodia riel & 7 & 0 & 0 & 0 & 0.0387 & 0.0587 & 0 & 0 \\
\hline Canada dollar & 10 & 0 & 0 & 0 & 0.0528 & 0.0488 & 0 & 0 \\
\hline Cape Verde escudo & 7 & 0 & 0 & 0 & -0.0099 & -0.0103 & 0 & 0 \\
\hline Chile peso & 10 & 0.8431 & 0.1757 & -0.7009 & 0.0396 & 0.0271 & 0.0838 & 0.0619 \\
\hline China yuan renminbi & 4 & 0 & 0 & 0 & -0.0670 & -0.3056 & 0 & 0 \\
\hline Colombia peso & 10 & 0.9833 & 0.0500 & -0.0252 & -0.0610 & -0.0371 & 0.1024 & 0.0650 \\
\hline Congo Democratic Republic franc & 13 & 0 & 0 & 0 & 0.0080 & 0.0181 & 0 & 0 \\
\hline Costa Rica colón & 7 & 0.9924 & 0.0653 & -1.6908 & 0.1110 & 0.1989 & 0.1093 & 0.2023 \\
\hline Dominican Republic peso & 12 & 0 & 0 & 0 & 0.0504 & 0.1180 & 0 & 0 \\
\hline Ecuador sucre & 14 & 0 & 0 & 0 & 0.0000 & 0.0000 & 0 & 0 \\
\hline Egypt pound & 4 & 0 & 0 & 0 & -0.0272 & -0.0667 & 0 & 0 \\
\hline El Salvador colón & 1 & 0 & 0 & 0 & -0.0007 & -0.1559 & 0 & 0 \\
\hline Equatorial Guinea epkwele & 2 & 0 & 0 & 0 & -0.0258 & -0.0608 & 0 & 0 \\
\hline Ethiopia birr & 7 & 0 & 0 & 0 & 0.0564 & 0.1722 & 0 & 0 \\
\hline Fiji dollar & 10 & 0 & 0 & 0 & -0.0147 & -0.0176 & 0 & 0 \\
\hline Gambia dalasi & 8 & 0.9044 & 1.2286 & -0.3230 & 0.0461 & 0.0301 & 0.1944 & 0.1831 \\
\hline Ghana new cedi & 8 & 0.8884 & 1.1623 & -1.6024 & 0.1150 & 0.3954 & 0.1053 & 0.3615 \\
\hline Guinea franc & 10 & 0 & 0 & 0 & 0.0588 & 0.0720 & 0 & 0 \\
\hline Guinea-Bissau escudo/peso & 15 & 0 & 0 & 0 & 0.0000 & 0.0000 & 0 & 0 \\
\hline Guyana dollar & 7 & 0 & 0 & 0 & 0.0062 & 0.0143 & 0 & 0 \\
\hline Haiti gourde & 12 & 0.9075 & 0.6771 & -0.9062 & 0.0708 & 0.1696 & 0.0482 & 0.1417 \\
\hline Honduras lempira & 7 & 0 & 0 & 0 & 0.0038 & 0.0105 & 0 & 0 \\
\hline Hong Kong dollar & 2 & 0.8182 & 1.9221 & -0.8663 & 0.0000 & 0.0002 & 0.0144 & 0.2278 \\
\hline India rupee & 8 & 0.9336 & 0.4619 & -0.0105 & 0.1010 & 0.1394 & 0.0681 & 0.0965 \\
\hline Indonesia rupiah & 12 & 0.8412 & 0.6069 & -0.0118 & -0.0263 & -0.0608 & 0.0415 & 0.1058 \\
\hline Israel new shekel & 10 & 0.9012 & 0.8238 & -0.1280 & -0.0762 & -0.0495 & -0.0207 & -0.0142 \\
\hline Jamaica dollar & 7 & 0.4626 & 1.9914 & -0.6054 & 0.0174 & 0.0658 & 0.0143 & 0.1173 \\
\hline Japan yen & 13 & 0.9191 & 0.6894 & -0.0358 & -0.0195 & -0.0155 & -0.0865 & -0.0730 \\
\hline Jordan dinar & 4 & 0 & 0 & 0 & -0.0006 & -0.0039 & 0 & 0 \\
\hline Kazakhstan tenge & 8 & 0.8926 & 0.4669 & -0.2301 & -0.0084 & -0.0680 & -0.0019 & -0.0164 \\
\hline Kenya shilling & 8 & 0.4322 & 1.2435 & -0.4127 & 0.0716 & 0.0333 & -0.0728 & -0.0483 \\
\hline South Korea won & 12 & 0.8258 & 1.6384 & -0.0429 & 0.1460 & 0.1229 & 0.0842 & 0.0719 \\
\hline Kuwait dinar & 4 & 0 & 0 & 0 & -0.0232 & -0.0704 & 0 & 0 \\
\hline Kyrgyzstan som & 8 & 0.9287 & 0.6811 & -0.1067 & -0.0215 & -0.0313 & 0.0508 & 0.0774 \\
\hline Lebanon pound & 2 & 0 & 0 & 0 & -0.0042 & -0.0504 & 0 & 0 \\
\hline
\end{tabular}


Table 1. Continued

\begin{tabular}{|c|c|c|c|c|c|c|c|c|}
\hline Currencies & Last regime & $q$ & $k_{1}$ & $k_{2}$ & $\mathrm{~B} \& \mathrm{H}$ & Sharpe-B\&H & Taylor & Sharpe-Taylor \\
\hline Lesotho loti & 2 & 0.9804 & 0.5634 & -0.0718 & 0.1361 & 0.0672 & -0.0714 & -0.0421 \\
\hline Madagascar ariary & 12 & 0.9669 & 0.8699 & -0.1247 & -0.0896 & -0.1461 & 0.0925 & 0.1574 \\
\hline Malawi kwacha & 7 & 0 & 0 & 0 & 0.0222 & 0.0558 & 0 & 0 \\
\hline Malaysia ringgit & 8 & 0 & 0 & 0 & 0.0206 & 0.0305 & 0 & 0 \\
\hline Maldive Islands rufiyaa & 4 & 0 & 0 & 0 & 0.0124 & 0.0750 & 0 & 0 \\
\hline Mauritania ouguiya & 7 & 0 & 0 & 0 & -0.0907 & -0.1858 & 0 & 0 \\
\hline Mauritius rupee & 8 & 0.9914 & 1.2347 & -0.7250 & 0.0318 & 0.0355 & 0.0015 & 0.0022 \\
\hline Mexico new peso & 12 & 0 & 0 & 0 & -0.0729 & -0.1160 & 0 & 0 \\
\hline Moldova leu & 8 & 0.8707 & 1.0659 & -0.1055 & -0.1620 & -0.4139 & 0.1689 & 0.4505 \\
\hline Mongolia tugrik & 4 & 0 & 0 & 0 & -0.0155 & -0.2092 & 0 & 0 \\
\hline Morocco dirham & 7 & 0 & 0 & 0 & 5.3454 & 0.0808 & 0 & 0 \\
\hline Mozambique new metical & 8 & 0 & 0 & 0 & -11.2791 & -0.0491 & 0 & 0 \\
\hline Myanmar (Burma) kyat & 15 & 0 & 0 & 0 & 0.0000 & 0.0000 & 0 & 0 \\
\hline Namibia dollar & 2 & 0 & 0 & 0 & 0.1273 & 0.0678 & 0 & 0 \\
\hline Nepal rupee & 8 & 0 & 0 & 0 & 0.0980 & 0.1516 & 0 & 0 \\
\hline New Zealand dollar & 12 & 0.9725 & 0.8684 & -0.0735 & -0.0907 & -0.0671 & 0.0268 & 0.0236 \\
\hline Nicaragua cordoba oro & 7 & 0 & 0 & 0 & -3.3268 & -0.0796 & 0 & 0 \\
\hline Nigeria naira & 12 & 0.9977 & 0.8403 & -0.1327 & -0.0047 & -0.0327 & 0.0163 & 0.1715 \\
\hline Pakistan rupee & 7 & 0 & 0 & 0 & 0.2013 & 0.1632 & 0 & 0 \\
\hline Papua New Guinea kina & 7 & 0.9674 & 0.5295 & -0.3155 & 0.0839 & 0.2011 & -0.0080 & -0.0193 \\
\hline Paraguay guarani & 10 & 0.6637 & 1.0996 & -0.1296 & -0.1766 & -0.2685 & 0.1715 & 0.2703 \\
\hline Peru new sol & 8 & 0.9843 & 1.3296 & -0.0820 & -0.0158 & -0.0151 & 0.0148 & 0.0148 \\
\hline Philippines peso & 8 & 0.9834 & 0.2385 & -0.0077 & 0.1000 & 0.1100 & 0.0865 & 0.1015 \\
\hline Qatar riyal & 2 & 0 & 0 & 0 & -0.0010 & -0.0115 & 0 & 0 \\
\hline São Tomé and Príncipe dobra & 10 & 0 & 0 & 0 & 0.0362 & 0.0720 & 0 & 0 \\
\hline Saudi Arabia riyal & 4 & 0.9832 & 1.3994 & -0.0360 & -0.0007 & -0.0097 & 0.0342 & 0.4572 \\
\hline Seychelles rupee & 8 & 0.7919 & 0.0165 & -0.0198 & 0.0009 & 0.0125 & 0.0059 & 0.0855 \\
\hline Sierra Leone leone & 4 & 0 & 0 & 0 & 0.0081 & 0.0400 & 0 & 0 \\
\hline Singapore dollar & 11 & 0.9852 & 0.6078 & -0.4699 & -0.0159 & -0.0271 & 0.0537 & 0.0993 \\
\hline South Africa rand & 13 & 0.0486 & 0.7426 & -0.0711 & 0.1227 & 0.0620 & 0.0852 & 0.0464 \\
\hline Sri Lanka rupee & 7 & 0.0000 & 1.4485 & -0.8164 & -0.0091 & -0.0692 & 0.0008 & 0.0067 \\
\hline Sudan pound & 7 & 0 & 0 & 0 & 0.0234 & 0.0432 & 0 & 0 \\
\hline Suriname dollar & 2 & 0 & 0 & 0 & -0.0065 & -0.0444 & 0 & 0 \\
\hline Swaziland lilangeni & 2 & 0 & 0 & 0 & 0.1274 & 0.0665 & 0 & 0 \\
\hline Syria pound & 10 & 0 & 0 & 0 & -0.0018 & -0.0413 & 0 & 0 \\
\hline Tajikistan somoni & 7 & 0.9242 & 0.7146 & -0.5408 & -0.0144 & -0.1930 & 0.0290 & 0.4286 \\
\hline Tanzania shilling & 10 & 0 & 0 & 0 & 0.0077 & 0.0082 & 0 & 0 \\
\hline Thailand baht & 11 & 0.9470 & 1.0524 & -0.1202 & 0.1284 & 0.0985 & 0.0399 & 0.0326 \\
\hline Tonga pa'anga & 8 & 0 & 0 & 0 & 0.0232 & 0.0261 & 0 & 0 \\
\hline Trinidad and Tobago dollar & 7 & 0 & 0 & 0 & -0.0073 & -0.0111 & 0 & 0 \\
\hline Tunisia dinar & 8 & 0.9173 & 1.3829 & -1.7782 & -0.0015 & -0.0017 & 0.0353 & 0.0462 \\
\hline United Arab Emirates dirham & 2 & 0 & 0 & 0 & -0.0011 & -0.0699 & 0 & 0 \\
\hline British pound & 11 & 0 & 0 & 0 & -0.0804 & -0.0881 & 0 & 0 \\
\hline Uruguay peso & 8 & 0.7158 & 0.1159 & -1.1663 & -0.1131 & -0.2646 & 0.0222 & 0.0634 \\
\hline Venezuela bolivar fuerte & 15 & 0 & 0 & 0 & 0.0000 & 0.0000 & 0 & 0 \\
\hline Viet Nam dong & 7 & 0.9845 & 0.1441 & -0.0734 & 0.0348 & 0.0878 & 0.0278 & 0.0707 \\
\hline Zambia kwacha & 13 & 0 & 0 & 0 & -0.0610 & -0.0439 & 0 & 0 \\
\hline
\end{tabular}

Notes: (1) The predictions period ranks from 1 January 2008 until 31 December 2010.

(2) The parameters of Taylor's strategy were obtained through maximizing the Sharpe ratio by a genetic algorithm.

(3) In dark grey, evidence of trend is found at the $5 \%$ confidence level, but Taylor's strategy is not able to improve the $\mathrm{B} \& \mathrm{H}$ strategy.

(4) In light grey, evidence of trend is found at the 5\% confidence level, and Taylor's strategy overcomes the B\&H strategy.

(5) See text for the classification of de facto exchange-rate regimes. 
Taylor's strategy whose parameters are obtained by means of a genetic algorithm. The Sharpe ratio of both strategies is also reported.

As can be seen in Table 1, for the exchange rates series where the null hypothesis of random walk was rejected at a significant level of $5 \%$, the return obtained by B\&H strategy is higher than Taylor's strategy. This lack of predictive power is also confirmed by comparing Sharpe's ratios which are lower for the B\&H strategy. Note that for the series where the trend is not accepted, we have not applied Taylor's strategy.

The countries where the null in favour of trend is rejected may be divided into two groups:

- Currencies where Taylor's strategy is not able to improve the B\&H strategy, neither in return nor in Sharpe ratios. This happens in 14 of the 39 cases. For these currencies although, in theory, the trends detected could be employed to beat the market, in practice it does not, at least not in the prediction period considered. Taking into account that sufficient large and long-life trends in prices will make a market inefficient, such markets were probably inefficient during the years studied. However, Taylor's strategy is not able to exploit these inefficiencies with predicting purposes during the prediction period.

- Currencies where Taylor's strategy overcomes the B\&H strategy, as much in returns as in Sharpe ratios. This happens in 25 of the 39 cases and this behaviour is more frequent in intermediate exchange-rate regimes. These exchange markets were probably inefficient during the years studied, making it possible to exploit slight dependence between returns using Taylor's trend model after the trading period to generate profitable net returns even taking into account transaction costs.

\section{Concluding Remarks}

The profitability of technical trading strategies in foreign exchange markets can be explained by a large class of nonlinear prediction rules potentially deriving from nonlinear versions of structural models such as chaos models by Gilmore (1993), target-zone models by Krugman (1991), monetary model by Meese and Rose (1991), self-exciting threshold autoregressive model by Krager and Kugler (1993), Autoregressive Conditional Heteroskedasticity (ARCH) models by Diebold and Pauly (1988) or Markov switching models by Dewachter (2001). Although these models fit insample the data with acceptable level, out-of-sample tests of these models indicate that their short-term forecasts have little success with respect to the random walk model. In contrast, this article provides additional evidence that trading strategies without theoretical foundation are able to improve the predictions of the random walk model, even taking into account the existence of transaction costs. So, the success of technical trading rules in the foreign exchange market constitutes a major puzzle in international finance.

We believe that our article contributes to the literature by applying a methodological innovation as well as our findings of the presence of economically exploiting trends in exchange rates for a wide sample of countries and exchange-rate regimes.

The results in this article indicate that there exists potential for investors to generate excess returns in exchange-rate markets by adopting technical trading rules-based one-step-ahead forecasts of returns produced by Taylor's (1980) price trend model. In particular, we find that Taylor's strategy overcomes the buy-and-hold strategy in 25 of the 39 cases where trends are detected, even in the presence of transaction costs.

Therefore, this article has showed the potential usefulness of Taylor's price trend model for technical trading rules to forecast daily exchange data when the model parameters are estimated by maximum likelihood using genetic algorithms.

\section{Acknowledgements}

The authors thank Ethan Ilzetzki for providing us with the updated database on exchange-rate arrangements. The authors gratefully acknowledge financial support from the Spanish Ministry of Science and Innovation, through the research projects ECO200805565 and ECO2010-21318. Adrián Fernández-Pérez also acknowledges the financial support from INNOVA CANARIAS 2020.

\section{References}

Chang, K. P. and Osler, C. (1999) Methodical madness: technical analysis and the internationality of exchangerate forecasts, The Economic Journal, 109, 636-61.

Dewachter, H. (2001) Can Markov switching models replicate chartist profits in the foreign exchange market?, Journal of International Money and Finance, 20, 25-41.

Diebold, F. and Pauly, P. (1988) Endogenous risk in a portfolio-balance rational-expectations model of the deutschemark-dollar rate, European Economic Review, 32, 27-53.

Dooley, M. P. and Shafer, S. (1983) Analysis of short-run exchange rate behavior: March 1973-November 1981, in Exchange Rate and Trade Instability: Causes, Consequences and Remedies (Eds.) D. Bigman and T. Taya, Ballinger, Cambridge, MA, pp. 43-72. 
Dorsey, R. D. and Mayer, J. M. (1995) Genetic algorithms for estimation problems with multiple optima, nondiferentiability, and other irregular features, Journal of Business and Economic Statistics, 13, 53-66.

Fernández-Pérez, A., Fernández-Rodríguez, F. and SosvillaRivero, S. (forthcoming) Detecting trends in the foreign exchange markets, Applied Economics Letters.

Gençay, R. (1999) Linear, non-linear and essential foreign exchange rate prediction with simple technical trading rules, Journal of International Economics, 47, 91-107.

Gilmore, C. G. (1993) A new test for chaos, Journal of Economic Behavior and Organization, 22, 209-37.

Harris, R. D. F. and Yilmaz, F. (2009) A momentum trading strategy based on the low frequency component of the exchange rate, Journal of Banking and Finance, 33, 1575-85.

Ilzetzki, E. O., Reinhart, C. M. and Rogoff, K. S. (2011) Exchange rate arrangements entering the 21st century: Which anchor will hold?, mimeo, University of Maryland, College Park, MD and Harvard University, Cambridge, MA.

Korajczyk, R. E. and Sadka, R. (2004) Are momentum profits robust to trading costs?, Journal of Finance, 59, 1039-82.

Krager, H. and Kugler, P. (1993) Nonlinearities in foreign exchange markets: a different perspective, Journal of International Money and Finance, 12, 195-208.

Krugman, P. (1991) Target zones and exchange rate dynamics, Quarterly Journal of Economics, 106, 669-82.
LeBaron, B. (1998) Technical trading rules and regime shifts in foreign exchange, in Advanced Trading Rules (Eds.) E. Acar and S. Satchell, Butterworth-Heinemann, Oxford, pp. 5-40.

Lesmond, D. A., Schill, M. J. and Zhou, C. (2004) The illusory nature of momentum profits, Journal of Financial Economics, 71, 349-80.

Levich, R. M. and Thomas, L. R. (1993) The significance of technical trading-rule profits in the foreign exchange market: a bootstrap approach, Journal of International Money and Finance, 12, 451-74.

Meese, R. A. and Rose, A. K. (1991) An empirical assessment of non-linearities in models of exchange rate determination, Review of Economic Studies, 58, 603-19.

Neely, C., Weller, P. and Dittmar, R. (1997) Is technical analysis in the foreign exchange market profitable? A genetic programming approach, Journal of Financial and Quantitative Analysis, 32, 405-26.

Reinhart, C. M. and Rogoff, K. S. (2004) The modern history of exchange rate arrangements: a reinterpretation, Quarterly Journal of Economics, 119, 1-48.

Taylor, S. (1980) Conjectured models for trends in financial prices, tests and forecasts, Journal of the Royal Statistical Society, Series A, 13, 338-62.

Taylor, S. (2008) Modelling Financial Time Series, World Scientific, Hackensack, NJ.

Taylor, S. and Kingsman, B. G. (1978) Non-stationarity in sugar prices, The Journal of the Operational Research Society, 29, 971-80. 